\title{
La rebelión de los límites, la crisis de la deuda y el vaciamiento de la democracia
}

Franz Hinkelammert

RESUMEN. Vivimos en una economía que depende del crecimiento, pero cada vez se hace más obvio que el crecimiento está llegando a sus límites. Parece difícilmente posible mantener un nivel de crecimiento como en las décadas pasadas. Lo que se puede esperar son aumentos del crecimiento a plazos más bien cortos que pronto volverán a colapsar: una especie de decadencia del sistema. Esto tienen que tomarlo en cuenta todos los planes de una reactivación del crecimiento.

Hemos derribado todos los límites y llegamos hoy a nuevos límites, cuya existencia la humanidad antes ni sospechaba. El ser humano resulta ser un ser infinito atravesado por la finitud.

Vivimos en una economía que depende del crecimiento, pero cada vez se hace más obvio que el crecimiento está llegando a sus límites. 


\section{Las amenazas globales}

- stamos enfrentados a tres - grandes amenazas globales concretas: la exclusión de la población, la subversión de las relaciones sociales y la amenaza a la naturaleza. Sin embargo, la mayor amenaza es otra: es la inflexibilidad absoluta de la estrategia de globalización. Es, de hecho, la verdadera amenaza. Lo es porque esta amenaza hace imposible enfrentar las otras amenazas mencionadas.

Se trata de una estrategia que de ninguna manera es un producto necesario de un mundo hecho global. En realidad, la estrategia de globalización es completamente incompatible con el hecho de que el mundo ha llegado a ser un mundo global. Ese es el verdadero problema. La estrategia de globalización destruye un mundo hecho global y es incompatible con la existencia de este mundo.

El mercado no es un sistema autorregulado. Las Ilamadas fuerzas de autorregulación del mercado no existen. Lo que hay es una determinada autorregulación de mercados particulares, no del mercado en su conjunto. El mercado como conjunto no tiene la más mínima tendencia al equilibrio, sino tiende siempre de nuevo y sistemáticamente a desequilibrios. El mercado es pura voluntad de poder.

Las mencionadas amenazas globales concretas son desequilibrios del mercado. A favor de ciertos equilibrios financieros, estas amenazas globales son sistemáticamente aumentadas.

La política del crecimiento económico muestra todavía otro lado: cuanto más se insiste en una ciega política de crecimiento, tanto más aumentan las amenazas globales $y$, como consecuencia, se sacrifica cualquier política que intente enfrentarlas. Esa es la lógica de la estrategia de globalización.

La estrategia de globalización se presenta a sí misma como política de crecimiento, pero no es simplemente eso. Hay que recordar solamente las características de esta estrategia para mostrar lo que es. Es la comercialización de todas las relaciones sociales, es la privatización como política, que obedece solamente a principios sin consideración mayor de la propia realidad. Por eso ni pregunta dónde la privatización sería la solución más adecuada y dónde precisamente la propiedad pública resulta la mejor solución. El hecho de que la privatización del Metro en Berlín (S-Bahn) arruinó este metro, no es ningún argumento en contra de su privatización. No hay argumentos en contra de determinadas privatizaciones porque solamente hay artículos de fe. Según esta fe, todas las esferas de la vida tienen que ser sometidas al mercado, lo que significa usarlas para inversiones del capital. No so- 
lamente cualquiera de los servicios públicos, también las cárceles y los ejércitos. Por supuesto, igualmente el sistema de educación, el sistema de salud y del seguro de vida.

Eso se presenta como si fuera política de crecimiento, pero es obvio que es principalmente una política de acumulación total de capital.

En nuestro idioma orwelliano todo es lo mismo: la globalidad del mundo, la estrategia de globalización y la totalización del mercado y de la acumulación del capital. Con esto, también el sometimiento de todas las decisiones bajo el cálculo de costos y utilidades.

Lo que no se puede percibir es la contradicción fundamental de nuestra sociedad actual: se trata de la contradicción entre un mundo hecho global y la universalización de esta estrategia de globalización.

Esta política de maximización del crecimiento ha llegado hoy a sus límites. Lo que anunciaba el informe del Club de Roma en 1972 bajo el título "los límites del crecimiento", se ha hecho real hoy. La crisis de 2008 no es simplemente una crisis del sistema financiero, sino el comienzo de una crisis producida por los límites del crecimiento que se hacen notar constantemente y que no tiene remedio. Lo que se da es la rebelión de los límites.
La crisis de 2008 estalló después de un extraordinario aumento del precio del petróleo. Eso llevaba a dificultades de pago, que obligaron a la venta de títulos financieros, los cuales resultan ahora no tener casi valor en el mercado. Eso llevó a una crisis financiera en la cual colapsó la burbuja financiera del sistema financiero. Los límites del crecimiento llevaron a esta crisis financiera, que se reforzó a sí misma por el hecho de que todo el sistema financiero resultó corrupto porque se basaba en títulos financieros sin ningún valor.

Desde 1987 hasta 2007 el consumo de petróleo aumentó aproximadamente un tercio. Se trata de un aumento de alrededor de $1.5 \%$ con un crecimiento económico de alrededor del 5\%. Este crecimiento no habría sido posible sin el correspondiente aumento del consumo de petróleo y, por eso, sin un aumento correspondiente de la producción de petróleo. Volver a un crecimiento parecido del consumo de petróleo en los próximos 20 años parece más bien imposible. En cuanto que todavía no hay un sustituto importante para el petróleo, parece entonces también imposible un crecimiento del producto social mundial de este tamaño.

No solamente el petróleo marca límites. En todos los sectores de la economía aparecen productos imprescindibles para un proceso de crecimiento comparable que 
escasean sin que se encuentren sustitutos adecuados con la velocidad necesaria. Igualmente cambia la situación mundial de partida. La crisis del clima definirá cada vez más límites de este proceso de crecimiento, que en algún momento tendrán que ser tomados en cuenta.

La búsqueda de sustitutos para el petróleo tiene inclusive consecuencias perversas. Hoy la producción agraria todavía aumenta, pero la producción de alimentos tiende más bien a la baja. El maíz, la soya, el aceite de palma, el azúcar y muchos otros productos se transforman en combustible para automóviles. En los Estados Unidos, es el caso de más de un tercio de la producción del maíz. En el siglo XVI se decía en Inglaterra: las ovejas devoran a la gente. Esta situación llevó a un terror tal frente a la población expulsada del campo, que el robo de una gallina fue castigado con la pena capital. Hoy tendríamos que decir nosotros: los automóviles devoran a la gente. Los autos tienen altos ingresos, los hambrientos, en cambio, no tienen ningún poder de compra. Lo que hoy se entiende por acción racional es que los autos, en nombre de la acción racional, tienen que tener preferencia. El concepto de racionalidad de nuestra teoría de la acción racional vigente es perfectamente perverso. ${ }^{1}$

Por esta razón, parece difícilmente posible mantener un nivel de crecimiento como en las décadas pasadas. Lo que se puede esperar son aumentos del crecimiento a plazos más bien cortos que pronto volverán a colapsar: una especie de decadencia del sistema. Esto tienen que tomarlo en cuenta todos los planes de una reactivación del crecimiento.

Hemos derribado todos los límites y llegamos hoy a nuevos límites, cuya existencia la humanidad antes ni sospechaba. El ser humano resulta ser un ser infinito atravesado por la finitud. Se trata de la finitud del ser humano, que ha descubierto que es infinito y que precisamente por eso choca de nuevo con la finitud. Pero no es la finitud del pensamiento anterior, como, por ejemplo, del pensamiento griego.

\section{Las crisis de la deuda}

Hasta ahora hemos hablado de desequilibrios provocados e inauditamente reforzados por el mercado de mercancías: la exclusión de la población, la subversión de las relaciones sociales y la amenaza a la naturaleza. Se trata de desequilibrios de la vida real. Pero también aparecen desequilibrios en relación al mercado mismo que refuerzan de manera inaudita los desequilibrios de la vida real mencionados. El desequilibrio más importante en este sentido resulta de los procesos de endeudamiento. 
Hoy nos encontramos de nuevo en uno de estos procesos de endeudamiento que esta vez se refiere sobre todo a los países europeos. El endeudamiento llega a un tamaño tal que se hace impagable para los países más endeudados. Este hecho de que la deuda se hace impagable es precisamente el negocio de los bancos. Para las burocracias privadas de las empresas grandes y de los bancos se trata de la gran oportunidad. Los países endeudados ahora son pillados sin la más mínima posibilidad de defenderse. Todo lo que resulta interesante para el capital ahora se vende a precios mínimos. Sin embargo, las deudas no bajan, sino que muchas veces aumentan. Los económicamente más potentes de los países afectados tienen participación en este negocio, aunque sea solamente como socios menores. El país que no puede pagar, tiene que pagar por lo menos lo que puede perdiendo, así su independencia. Si se da un límite al endeudamiento, este límite aparece porque se puede pillar solamente lo que hay. Se hace el cálculo de la mafia cuando calcula el "protection money". Sacará lo más que se puede, pero tampoco demasiado para que se pueda seguir robando en el futuro. Los países endeudados pierden su autonomía y los bancos maximizan - como actores "racionales" que son- su protection money.

Hemos tenido una situación de endeudamiento parecido en los años ochenta en América Latina. Los ajustes estructurales que se impuso a estos países, Ilevaron al pillaje de todo un continente. El estado social fue disuelto en gran parte y se privatizó lo que se podía privatizar. Se produjo una inaudita miseria de las poblaciones y una destrucción de la naturaleza más grandes que en cualquier época histórica anterior. El endeudamiento era la palanca que hizo posible someter toda América Latina a la estrategia de globalización, que es ciega y jamás da razones.

Los mismos ajustes estructurales son hoy impuestos a los países endeudados de Europa, pero los imponen esta vez los propios Estados de Europa, que lo hacen porque el capital tiene el poder de imponer esta política a estos mismos Estados. Las crisis de la deuda se transforman en gigantescos procesos de expropiación, que conforman una especie de acumulación originaria que acompaña toda la historia del capitalismo.

No quiero intentar presentar lo que podría ser la solución. Quiero más bien presentar el hecho de que en nuestra historia hay un caso, en el cual se solucionó una crisis de endeudamiento de una manera tal que se evitaba desatar estos procesos de destrucción. Eso ocurrió en el caso de la crisis de endeudamiento que resultó al fin de la II Guerra Mundial. Una crisis de la deuda comparable había ocurrido 
después de la I Guerra Mundial. Sin embargo, en este caso no se buscaba una solución, sino que sencillamente se impusieron pagos máximos sin considerar siquiera las consecuencias destructivas resultantes. Esta ceguera dogmática ha sido una de las razones principales para el posterior éxito del nazismo en Alemania, que llevó a la II Guerra Mundial. Ya Keynes, que había participado en las negociaciones de paz de Versalles en 1919, advirtió sobre el peligro de un desarrollo de este tipo como consecuencia de la actitud de los ganadores, en su libro sobre estas negociaciones.

El tratamiento de la crisis de la deuda después de la II Guerra Mundial ha sido muy diferente. Hasta se puede decir que era muy razonable y acertado. Quiero brevemente sintetizar esta política, para discutir posteriormente por qué ha sido posible después de la II Guerra Mundial y por qué hoy no se saca ningún aprendizaje de esta experiencia. Al contrario, ni se menciona esta experiencia.

En su esencia, se trataba de las siguientes medidas que se aplicaban coordinadamente:

1. Se partía de una anulación casi completa de todas las deudas de Europa Occidental inclusive Alemania. Se la dio en parte como moratoria de largo plazo. Durante el tiempo de estas moratorias sobre las deudas no pagadas no se calculaban intereses. Eso se fijó en el acuerdo de Londres sobre las deudas en 1953.

2. Encima de esta postergación del pago, se concedieron nuevos créditos sin intereses y sin devolución a largo plazo. Se trata de los créditos del plan Marshall. Se transformaron en los países receptores en revolving funds.

3. Se fundó una Unión Europea de Pago para evitar el surgimiento de nuevas relaciones de endeudamiento entre los países europeos incluidos. Los desequilibrios de la balanza comercial entre estos países no fueron financiados por créditos comerciales. Los saldos positivos de los países más exitosos financiaron los déficits de los otros países sin cobrar intereses.

4. Altos impuestos sobre los ingresos de capital y los altos ingresos en general. Impuestos a las herencias, a las propiedades.

5. Se fundó el Estado social. Aumentaron significativamente los gastos sociales en lo que se Ilamó después el Estado de bienestar. Eso después también se llamaba el rostro humano del capitalismo.

Ese es el núcleo de esta política muy razonable que ha tenido un 
éxito considerable. Sin esta política, la recuperación económica de Europa habría demorado mucho más.

La pregunta que tenemos que hacernos es la siguiente: ipor qué era posible esta política después de la II Guerra Mundial y no después de la I Guerra Mundial? Y la otra pregunta: ¿por qué era posible esta política después de la II Guerra Mundial, sin embargo, es imposible frente a la actual crisis de la deuda y no era posible tampoco en los años 80 en América Latina?

La razón debe ser clara. Estaba empezando la guerra fría en relación con la Unión Soviética y había partidos comunistas muy fuertes sobre todo en Francia e Italia. El sistema capitalista parecía amenazado en su propia existencia.

El sistema percibió el peligro y por eso reaccionó como un sistema global. Eso llevó a medidas completamente incomprensibles desde el punto de vista de la lógica del capitalismo, pero se hacen comprensibles como medidas de guerra en la guerra fría. En este sentido se trataba de una economía de guerra que interrumpió la lógica del capitalismo en el interior mismo de este capitalismo. Inclusive los altos gastos sociales desde el punto de vista del poder económico eran gastos de guerra, en el fondo, dinero botado que había que gastarlo sencillamente por la razón de que había que ganar una guerra.
El hecho de que se trata efectivamente de costos de guerra se ve también en que los Estados Unidos renunció al pago de las deudas de la guerra en relación con los países de Europa occidental, pero no al pago de las altas deudas de guerra de la Unión Soviética del Lend-Lease-Act de 1941 —alrededor de 10 mil millones de dólares. Se quería hacer negocio "as usual". Cuando la Unión Soviética rechazó esta exigencia, se la denunció por incumplimiento de contrato.

Estas medidas tomadas limitaron extraordinariamente el poder de la banca y su negocio con la miseria de las poblaciones. Efectivamente renunciaron y hasta participaron en la planificación de estas medidas para salvar el sistema. No lo hicieron para tomar en cuenta las necesidades de la población.

Efectivamente, sin estas medidas habría resultado algo posiblemente inclusive peor de lo que pasó después de la I Guerra Mundial.

Eso demuestra muy bien que los banqueros, pero también los políticos, saben muy bien la catástrofe perfectamente innecesaria que origina su política de cobro ciego de la deuda y que igualmente saben muy bien cuál sería la solución efectiva $-y$ además humana- de una crisis de la deuda. Escogen conscientemente el crimen implicado en la imposición del pago indiscriminado. 
Sin embargo, hoy no ven ninguna razón para medidas de este tipo, porque no hay una resistencia correspondiente. Tampoco vieron ninguna razón para tales medidas durante la crisis de la deuda de los años 80 en América Latina y en el tercer mundo. En el tiempo de Reagan se decía eso en los Estados Unidos muy abiertamente: ¿para qué seguir botando el dinero y botar las perlas a los chanchos, si el peligro para el sistema ya pasó? Y nuestros medios de comunicación nos presentan eso todos los días.

Los banqueros y los políticos saben hoy igualmente muy bien las catástrofes sociales que están produciendo, pero no ven la más mínima razón para limitar el negocio que se está haciendo con la miseria de las poblaciones y de la naturaleza. La prueba para el hecho que todo eso también se ve hoy, está en el hecho de que se veía eso perfectamente después de la II Guerra Mundial, pero casi nadie habla. Sacrificamos vidas humanas y realizamos grandes genocidios y lo sabemos en nuestro subconsciente. Los economistas inventan cualquier cosa para tener pretextos y para eso son pagados. Todos saben, pero casi todos respetan el tabú tan bien guardado alrededor de estos genocidios.

Lo que ha sido la solución después de la II Guerra Mundial, es en la historia del capitalismo absolutamente único. Las crisis de la deuda son un negocio demasiado bueno para renunciar a él, a no ser que resulte inevitable renunciar a este negocio para asegurar la propia existencia del sistema. Cuanto peor la crisis de la deuda, mejor el negocio que ofrece cuando resulta que un país ya no puede pagar. En este caso, al prestamista le pertenece todo lo que hay en el país. Lo podemos ver hoy en Grecia, donde está en camino un genocidio económico de este tipo. Eso se va a extender a muchos países más. Al final, Ilega hasta a los países dominantes, porque el poder económico quiere también un pillaje del propio país de la misma manera como antes en países extranjeros. Estados Unidos ha progresado más en este sentido, pero también Alemania tendrá exactamente lo mismo después de haber acabado con los otros países de Europa.

Si todo eso no es suficiente, los gobiernos de los países poco endeudados tienen que respaldar las deudas de los otros para que no quiebre la banca y pueda seguir haciendo su aporte para el "progreso". Sin embargo, nos acercamos a un nivel donde de repente ni la totalidad de todos los gobiernos puede respaldar estas deudas. Cuando se pueden pagar las deudas solamente con nuevas deudas, la deuda total crece sin ningún límite con la velocidad de la progresión del interés compuesto. Devoran todo. Inclusive los Estados Unidos se encuentran hoy en un automatismo tal de la deuda cuyo final nadie puede prever. 
Sin embargo, las medidas que se están tomando son exactamente lo contrario de lo que se hizo frente a la crisis de la deuda después de la II Guerra Mundial, pero ni se discute este hecho. Proponer hoy reaccionar a la actual crisis de la deuda de la manera como se lo hizo después de la II Guerra Mundial —por supuesto, sin copiar mecánicamente- es considerado algo de locos, además de extremista. Quien rechaza estos genocidios económicos es considerado extremista, y quien los apoya, es moderado y realista en nuestra sociedad hipócrita.

Para nosotros desde el punto de vista de esta nuestra sociedad hoy está claro: el capitalismo ya no necesita un rostro humano y por eso todos los gastos sociales y todas las consideraciones de una humanización de la sociedad significan dinero botado.

\section{El vaciamiento de la democracia}

Hemos indicado dos elementos decisivos de la actual crisis. Por un lado, la estrategia de globalización llegó a ser el obstáculo decisivo para lograr una respuesta frente a las grandes amenazas para nuestro mundo: la exclusión de partes cada vez mayores de la población mundial, la disolución interna de las relaciones sociales y la cada vez más visible destrucción de la naturaleza. Por el otro lado, la total subordinación de la política bajo el automatismo de la deuda se transformó en el motor de este proceso destructivo.

Son los países democráticos, es decir, aquellos países que arrogantemente se presentan como las democracias-modelo, que imponen esta política al mundo entero. Estos países hasta ahora tienen mayorías internas para esta política y declaran a todos los gobiernos que no aceptan incondicionalmente esta política, como no-democráticos. Si se someten a esta política, son democráticos, aunque sus presidentes se llamen Pinochet o Mubarak. Por lo menos son democráticos en su esencia, aunque no en su apariencia. Este criterio es el de las democracias-modelo, sobre todo de los Estados Unidos y de Europa. Con este criterio democratizan el mundo.

Pero, ¿por qué hay mayorías a favor de esta deficiencia mental? Brecht decía: solamente los terneros más grandes y tontos eligen ellos mismos sus carniceros (Nur die allergrössten Kälber wählen ihre Schlächter selber). Pero se sigue eligiéndolos. Aunque a veces no.

Se trata de lo que se llama la soberanía popular, que pretendidamente vale en las democraciasmodelo: todo poder sale del pueblo. Sin embargo, esta soberanía popular 
tiene un punto problemático. Hoy consiste en que el pueblo declara soberanamente que el poder económico y, por tanto, el Capital, es el soberano. La canciller alemana Merkel lo dice: "la democracia tiene que ser conforme al mercado". Eso se dice en un lenguaje muy específico. Se dice que el mercado es un ser autorregulado que no debe ser intervenido por ninguna voluntad humana y por tanto tampoco por la voluntad expresada en la elecciones del soberano popular. La Unión Europea entiende eso como el contenido central de su constitución.

Esa precisamente es la afirmación según la cual el Capital es el soberano que tiene que ser confirmado por la soberanía popular. Según nuestros apologetas de la soberanía del Capital, la soberanía popular deja de ser democrática si no afirma esta soberanía del Capital. En el lenguaje de Rousseau eso significa -aunque no corresponde completamente a lo que Rousseau dice-, que la voluntad general (volonté général) es esta decisión de la soberanía popular que declara y asume la soberanía del Capital y que esta no puede ser cambiada por la voluntad de todos (volonté de tous). Por tanto, la soberanía popular que no afirma la soberanía del Capital es antidemocrática, inclusive totalitaria. Sin embargo, Pinochet y Mubarak son democráticos por el hecho de que imponen la voluntad general (volonté général), aunque no sean elegidos. Son conformes al mercado, como lo dice Frau Merkel.

Ese es el vaciamiento de la democracia, como ha tenido lugar en las democracias-modelo. El pueblo renuncia a su soberanía y la entrega al poder económico, que se hace presente como Capital. Los métodos para lograr esto son muchos. Solamente quiero mencionar dos, que tienen un carácter central: la creación de la opinión publica en el sentido de una opinión publicada y la amplia determinación de la política por el financiamiento de las elecciones.

El dominio sobre los medios de comunicación hoy está casi totalmente en las manos de sociedades de capital, que son sus propietarias. Estos medios de comunicación se basan en la libertad de prensa, que es la libertad de los propietarios de los medios de comunicación. Estos se financian por una especie de subvenciones en la forma de propaganda comercial pagada, que son pagadas por otras sociedades de capital principalmente. Cuanto más presupuestan los medios de comunicación grandes capitales, se transforman en instancias de control de la opinión pública y, por tanto, de la libertad de opinión. Para estos medios de comunicación no hay otra libertad de opinión que la libertad particular de sus propietarios y sus fuentes de financiamiento. Esta la garantiza la libertad de prensa. 
El derecho humano no es la libertad de prensa, sino la libertad de opinión de todos y por tanto universal, pero al hacer de la libertad de prensa el único criterio para los derechos de la opinión en los medios de comunicación, la libertad de prensa se ha transformado en un instrumento sumamente eficaz para el control de la libertad de opinión universal. Este es limitado, aunque solamente en cierto grado, por los medios de comunicación públicas, en cuanto tengan una autonomía efectiva. Berlusconi como propietario de la gran mayoría de medios de comunicación en Italia podía expresar hasta con trompetas su opinión sin casi ninguna contestación. Sin embargo, uno de los canales de televisión que le hizo la oposición más dura, era un canal de la televisión pública RAI. No lo podía intervenir, porque tenía una autonomía asegurada por el derecho. Por otro lado, el presidente Reagan aseguró su poder en buena parte por su indiscriminada política de privatización de los medios de comunicación, inclusive con un conflicto durísimo con la UNESCO, a la cual retiró su financiamiento. Con eso aseguró un dominio incontestado sobre el derecho humano de la libertad de opinión en los Estados Unidos.

Para los políticos se trata de un límite serio porque necesitan medios de comunicación para hacerse presentes ellos y también sus posiciones políticas. Pero la condi- ción para este acceso para ellos es reconocer el poder económico, por tanto, el capital como el soberano de hecho.

Una muy parecida situación se da en casi todos los procesos de elección. Un participante importante $y$ muchas veces decisivo en las elecciones es el poder económico como el verdadero soberano. Siempre está, pero su presencia es invisible y la podemos solamente derivar. Este Gran Otro está presente hasta cuando él mismo ni siquiera lo sabe. Está presente en las elecciones de los candidatos, en los discursos y en los medios de comunicación.

Con eso, la política recibe una nueva y muy importante función. Para tener éxito, casi siempre tiene que representar este gran otro frente a los electores a los cuales aparentemente siempre representa. Tiene que hacer eso en una forma en la que aparentemente los ciudadanos deciden ellos mismos por su propia voluntad que este gran otro es el soberano real. El político exitoso es entonces aquel cuya representación del Gran Otro es vivida por los ciudadanos como la propia decisión de ellos mismos.

Los indignados en España se dieron cuenta de este carácter de la democracia vaciada que los dominaba y les quita cualquier posibilidad de participación. Por eso exigieron "democracia real ya", frente a un sistema que se presenta, 
inclusive por medio de la policía, como la democracia verdadera.

La soberanía popular por eso no deja de ser algo real y efectivo. Que los ciudadanos tomen conciencia de la soberanía popular, es el gran peligro para esta democracia de las democracias-modelo. La soberanía popular no es el resultado de una ley que la reconoce, sino muy al contrario, la ley que la reconoce parte del hecho de que un pueblo que se sabe soberano y que actúa correspondientemente, es efectivamente soberano, haya ley o no. Se trata de esta soberanía popular que nuestras democracias tienen que transformar en soberanía del mercado y del Capital; pero con eso pueden fracasar, y eso temen cuando empiezan los levantamientos populares democráticos.

Estos levantamientos están hoy en curso y otros se anuncian. Empezamos en 2001 en Argentina. Paralelamente a eso aparecieron gobiernos de izquierda como en Venezuela, Bolivia y Ecuador, que rechazan poner la soberanía del mercado y del Capital en el lugar de la soberanía popular. En la opinión pública publicada de las democracias occidentales por eso son considerados no-democráticos.

Sin embargo, con una fuerza muy especial, aparecieron estos movimientos populares en el año 2011 en los países árabes, sobre todo de África del norte. Eso llevó entonces al movimiento de los indignados en España del mismo año.

En las democracias occidentales apareció la voz de alarma. Si se mostraba entusiasmo, casi siempre no era sino simple palabrería. Sin embargo, tenían que aceptar la democratización en algunos países árabes. En seguida se ofreció apoyo, pero este apoyo siempre hizo lo mismo: fundar democracias que ponen la soberanía del mercado y del Capital en el lugar de la soberanía popular. Quieren "democracias verdaderas". Eso parece ser más fácil cuando la rebelión de los movimientos populares se dirige en contra de regímenes dictatoriales, a pesar de que estos regímenes dictatoriales siempre han tenido anteriormente el apoyo casi absoluto de nuestras democracias-modelo. Amigos de la libertad, como Mubarak y Kadhafi, fueron por eso declarados monstruos de un día para otro. Antes eran buenos, ahora resultan malos. Sin embargo, detrás había solamente la preocupación de crear también en estos países democracias vaciadas como lo son hoy las democracias occidentales. Se trata de democracias como ya se han creado en Irak y Afganistán. Y está claro: los movimientos democráticos rebeldes no quieren para nada democracias-modelo como las creadas en Irak y Afganistán.

A eso siguieron los levantamientos democráticos en España y, por consiguiente, en el interior de 
una de estas democracias-modelo occidentales. También este movimiento quiere democracia. Dejan bien claro que se enfrentan a una democracia, en la cual los políticos - se trata de casi todos los políticos - hacen la política de los poderes del mercado y del capital y se hacen los representantes de estos como los poderes soberanos. En Argentina, en 2001, estos rebeldes gritaron: "ique se vayan todos!"

El nombre que se dio a este movimiento en España y que antes ya llevaron a cabo algunos movimientos árabes significa algo. Se Ilaman indignados. Eso significa que se sienten como seres humanos cuya dignidad ha sido despreciada y pisada. El mismo sistema dominante se transformó en un sistema de negación de la dignidad humana. ${ }^{2}$

Este movimiento se ha ampliado cada vez con nuevas ampliaciones de su contenido, manteniendo, sin embargo, su identidad. Eso ocurrió con las protestas en Chile en contra de la comercialización del sistema de educación y de salud. Lo mismo ocurrió al mismo tiempo en Estados Unidos con el movimiento "Ocupy Wall Street" y que se está ampliando al mundo entero. Uno de sus lemas era: Stop trading with our future. Pone otra vez la exigencia del reconocimiento de la dignidad humana en el centro.

Sin embargo, a la vez que presentan sus intereses, los presentan desde un punto de vista: de la dignidad humana. Eso está presente también en el fondo de los movimientos democráticos árabes. Los seres humanos protestan y se rebelan porque son violados en su dignidad humana. Y quieren otra democracia porque la violación de su dignidad humana es un producto de la propia lógica de la democracia vaciada. Estas democracias occidentales solamente pueden reírse al escuchar las palabras dignidad humana. Nada de eso existe, ese es el núcleo de esta nuestra democracia vaciada. El lugar de la dignidad humana lo ha ocupado la consideración del ser humano como capital humano, porque se cree que eso es "realista". Sin embargo, nos hace comprender de qué manera el Occidente vació muy democráticamente la dignidad humana y la hizo desaparecer. Se trata de la transformación del ser humano en capital humano y su total subordinación bajo el cálculo de utilidad. Ciertamente, capital humano no tiene dignidad humana, es máximo nihilismo.

De eso se trata la rebelión en nombre de la dignidad humana. $Y$ no solamente de la dignidad humana, también de la dignidad de la naturaleza. Los seres humanos no son capital humano y la naturaleza no es capital natural. Hay algo como la dignidad. Las democracias occidentales han olvidado eso desde mucho tiempo. Sin embargo, se trata de la recuperación de la dignidad humana: el tratamiento digno del ser 
humano, del otro ser humano, de sí mismo y de la naturaleza también.

Los indignados no hablan en nombre de intereses y de la utilidad por realizar. Hablan en nombre de su dignidad humana encima de la cual no puede haber ningún cálculo de utilidad. Seguramente, comer da utilidad. Pero no tener comida no es una baja de utilidad, sino una violación de la dignidad humana. Eso no puede cambiar ningún cálculo de la utilidad. Sin embargo, nuestra sociedad es tan deshumanizada, que este horizonte de dignidad humana casi ha desaparecido con el resultado de que casi todos se interpretan o se dejan interpretar como capital humano. Lo que tenemos que hacer con la persona humana, eso nos lo indica el mercado. $\mathrm{Y}$ el mercado dice lo que dicen nuestros banqueros. $Y$ los políticos dicen lo que antes han dicho los banqueros. Por eso, si el mercado lo indica como útil, en cualquier momento puede empezar el genocidio. El mercado entonces se transforma en lo que Stiglitz llamó las armas financieras de destrucción masiva, que hoy hacen su trabajo en Grecia y en España.

El poder económico deja morir, el poder político ejecuta. Ambos matan, aunque con medios diferentes. Por eso el poder político tiene que justificar el matar mientras el poder económico tiene que justificar por qué deja morir y no interviene en el genocidio dictado por el mercado. La que sea la justificación, ambos son asesinos. Ninguna de estas justificaciones es más que la simple ideología de obsesionados.

\section{El asesinato por medio del dejar morir}

La denuncia del asesinato ordenado por el poder económico tiene historia. En la Biblia judía es expresamente denunciado:

Mata a su prójimo quien le arrebata su sustento, vierte sangre quien quita el jornal al jornalero. Eclesiástico, 34, 22

Bartolomé de las Casas se decide a ser uno de los defensores de los indígenas de América basándose en este texto que lee y medita y a través del cual se convierte. Resulta que son los indígenas quienes son víctimas de asesinatos de este tipo. El eclesiástico denuncia igualmente este asesinato.
Al final del mismo siglo XVI asume Shakespeare este tipo de denuncia y la pone en la boca de Shylock, el personaje del Mercader de Venecia:

Me quitan la vida si me quitan los medios por los cuales vivo. 
Esta problemática aparece de nuevo en los siglos XVIII y XIX. Se comienza a hablar sobre el laissez faire: Laissez faire, laissez passer. Los críticos lo tomaron irónicamente: Laissez faire, laissez mourir.
Pero especialmente importante es Malthus que insiste en: laissez mourir en vez de laissez faire. Adam Smith dice eso mismo de la manera siguiente:

"En una sociedad civil, sólo entre las gentes de inferior clase del pueblo puede la escasez de alimentos poner límite a la multiplicación de la especie humana, y esto no puede verificarse de otro modo que destruyendo aquella escasez una gran parte de los hijos que producen sus fecundos matrimonios... Así es, como la escasez de hombres, al modo que las mercaderías, regulan necesariamente la producción de la especie humana: la aviva cuando va lenta y la contiene cuando se aviva demasiado. Esta misma demanda de hombres, o solicitud y busca de manos trabajadoras que hacen falta para el trabajo, es la que regula y determina el estado de propagación, en el orden civil, en todos los países del mundo: en la América Septentrional, en la Europa y en la China.»33 (Smith, 1983: 124)

En Adam Smith este dejar morir es ahora ley del mercado, lo que no es en Malthus. Según Smith, los mercados siempre dejan morir a aquellos que en el interior de las leyes del mercado no tienen posibilidad de vivir y así debe ser. Es parte de la ley del mercado. El equilibrio de la mano invisible se realiza dejando morir a aquellos que caen en la miseria. Si volvemos a la cita del eclesiástico, eso significa que el equilibrio se logra por el asesinato de los sobrantes.

Es claro que para Mathus y Smith la tesis del Eclesiástico, según la cual se trata de un asesinato, no es aceptable. Sin embargo, Marx insiste en eso y cita en el Tomo I del Capital la tesis correspondiente de Shakespeare, pero de esta manera también al Eclesiástico, del cual Shakespeare reproduce lo que dice. Por eso también Marx sostiene que las afirmaciones citadas de Malthus y Smith desembocan en el asesinato.

Es interesante el hecho de que Smith presenta este dejar morir como consecuencia de una ley del mercado. Por tanto hay un legislador que condena a la muerte y este es el mercado.

En esta forma, es decir, como ley, todo eso sigue válido hoy y lo vivimos precisamente ahora con la condena del pueblo griego a la 
miseria a la cual han seguido otras condenas y seguirán muchas más. El poder económico condena a la muerte por medio del mercado y ejecuta. Es la ley, es decir, la ley del mercado, que ordena estas condenas. Con eso da el permiso para matar y los portadores del poder económico resultan agentes 007.

Esta ley del mercado tiene dos dimensiones. Una es la de la ética del mercado, de la cual habla Max Weber. Hayek la sintetiza: garantía de la propiedad privada y cumplimiento de los contratos. El cumplimiento de los contratos implica el pago de las deudas. Esta ética del mercado es ética de cumplimiento ciego: no hay razones para someter sus normas, que todas son normas formales, a un criterio de juicio y de evaluación. Como dice Milton Friedman, valen por fe en el mercado. Vale un rigorismo ético absoluto.

Al lado de esta ética del mercado se trata de leyes del mercado del tipo del dejar morir a los seres humanos sobrantes, es decir, los que no tienen cabida en el mercado, según la cita de Smith. Leyes del mercado de este tipo constantemente son inventadas. Hoy toda la estrategia de globalización se considera ley del mercado que hay que cumplir ciegamente. Eso vale especialmente para el sometimiento de todas la relaciones sociales bajo las relaciones del mercado y la privatización en lo posible de todas las instituciones de la sociedad.

Ambas dimensiones de las leyes del mercado están íntimamente relacionadas. Una no existe sin la otra. Tienen en común su destructividad para la conveniencia humana, sea con los otros seres humanos, sea con la naturaleza entera. Se declara entonces esta destrucción resultante de destrucción creativa, de la cual hablaba Schumpeter, usando la expresión destrucción creativa de Bakunin sin citarlo obviamente. No se puede negar que existe esta destrucción, pero se la hace tolerable por ser pretendidamente creativa. No pesa sobre la conciencia moral, tanto más cuanto más ciegamente toda destructividad es declarada creativa. Quien no puede pagar con dinero, tiene que pagar con sangre. Ese es el principio del Fondo Monetario y de los bancos.

El caso mayor de estos genocidios de las últimas décadas ocurrió en Rusia. Dice un autor, basándose en un análisis de eso en la revista inglesa The Lancet:

"Observando que la población "perdió aproximadamente cinco años de esperanza de vida entre 1991 y 1994", los autores sostienen que semejante degradación de las condiciones de vida es consecuencia directa de las "estrategias económicas implementadas para pasar del comunismo al 
capitalismo". Las que habían sugerido, junto con otros, los money doctors franceses." 4

Se habían producido millones de muertes. Pero todo con muy buena conciencia. Tan buena conciencia, que los medios de comunicación casi no mencionaron este gran genocidio.

Los genocidios que se anuncian con el plan para Grecia posible- mente llegan a resultados parecidos. Tampoco se van a publicar mayormente.

La misma ley, en nuestro caso hoy, la ley del mercado, es transformada en la fuerza del crimen que se comete. Eso me recuerda a una afirmación de San Pablo:

La espina de la muerte es el crimen, la fuerza del crimen es la ley. $1^{a}$ Cor. $15,56^{5}$

La ley se transforma en la fuerza del crimen y activa la espina de la muerte. La ley soluciona todos los problemas de una posible mala conciencia de aquellos que cometen el crimen. Están cumpliendo una ley y por tanto no cometen ningún crimen. Precisamente eso ha ocurrido ahora con Grecia. El Fondo Monetario, el banco central europeo, el consejo europeo y los gobiernos de Merkel y Sarkozy son declarados inocentes del crimen que efectivamente cometen en nombre de una ley que la propia sociedad burguesa ha promovido. Se trata del corazón de piedra que tiene que ser cultivado en nuestros ejecutivos para ser capaces de hacer lo que hacen.

Si se actúa de esta manera, la conciencia moral se da vuelta y se invierte. Se tiene ahora mala consciencia si no se comete los crímenes. Son ahora un deber en el cumplimiento de la ley.

Eso dificulta mucho toda crítica de las violaciones de derechos humanos. Cuando Pinochet estaba prisionero en Londres por la sospecha de genocidio y de muchas otras violaciones de los derechos humanos, Margaret Thatcher Io visitó demostrativamente. Según su opinión, Pinochet había cumplido con la ley al perseguir violadores de la ley. Toda crítica de las violaciones de los derechos humanos de esta manera puede ser inmunizada.

Se da inclusive la posición al revés. Aquel que comete estas violaciones de los derechos humanos, se siente tan libre de cualquier crimen, que goza de manera sádica los sufrimientos de aquellos que está persiguiendo. Goza aquello que él considera como la justicia. De esta manera, el ejercicio del poder llega a ser goce del poder $y$, 
al final, goce del sufrimiento de los otros.

En el año 1991, el jefe de Nestlé, Maucher, escribió un artículo en la revista de los empresarios alemanes, en el cual declaró que necesitaba en su empresa ejecutivos con "Killerinstinkt", es decir, con el instinto para matar. ${ }^{6}$

No solamente Nestlé necesita "Killerinstinkt" para que resulten sus chocolates deliciosos, todo servicio secreto también lo necesita. No tendrían torturadores si no tuvieran personas con "Killerinstinkt". Killerinstinkt es el instinto de torturadores que viven en su acción su goce sádico. También la formación de las tal Ilamadas tropas de élite es la formación del "Killerinstinkt" en sus miembros. Se han desarrollado inclusive técnicas para fomentar este instinto. Este Killerinstinkt es necesario para la fomentación, tanto de la violencia directa, como de la violencia del dejar morir en nombre del mercado.

Se trata de goce de la desgracia y del dolor del otro. Se trata de sadismo. El sadismo es el aceite de la máquina del poder. Este hecho está visible por todos lados, pero casi todo el mundo se cuida mucho de analizarlo o denunciarlo. Es un secreto a voces.

\section{La alternativa}

Este asesinato ordenado por el mercado jamás es la única alternativa, aunque siempre es interpretada por los medios de comunicación como tal. Siempre existe la alternativa de la regulación y canalización de los mercados, como lo era posible después de la II Guerra Mundial, pero necesariamente es la intervención en los privilegios de aquellos que tienen el poder económico. Sin embargo, nuestra sociedad vive una idolatría del poder tal, que esa alternativa no es considerada con el resultado de que toda la sociedad se ha transformado en asesina y criminal.

Hoy la tarea es desarrollar una sociedad capaz de regular y canalizar el mercado en un grado tal, que ya no puede pronunciar condenas de muerte. Esa es la sociedad de la cual se trata.

\section{Consideraciones finales}

Para lo anterior, me he apoyado en un reciente extraordinario discurso de Theodorakis, como también en posiciones de Jean Ziegler. Las posiciones de este tipo en nuestros medios de comunicación son al unísono caracterizadas como extremismo. Participar en estos genocidios económicos es considerado realismo. Rechazarlo 
es extremismo. Así tiene que ser en una sociedad organizada por los responsables de estos genocidios.

Theodorakis estuvo presente en el tiempo de la ocupación militar de Grecia por las tropas alemanes durante la II Guerra mundial, en la cual se realizó un pillaje de todo el país y el asesinato de alrededor de un millón de personas. Fue miembro de la resistencia griega y conoció personalmente las cárceles de la Gestapo. Después de la guerra, Alemania, que era responsable, no tenía ninguna deuda con Grecia. De todas maneras, estas deudas eran impagables $y$, por tanto, fueron anuladas. Sin embargo, hoy Grecia debe a Alemania también sumas absolutamente impagables, pero Alemania no anula las deudas, sino exige su pago hasta el último peso. Otra vez Alemania hará en

\section{Notas}

1 Tomás Moro escribía en 1516: "But I do not think that this necessity of stealing arises only from hence; there is another cause of it, more peculiar to England.' 'What is that?' said the Cardinal: 'The increase of pasture,' said I, 'by which your sheep, which are naturally mild, and easily kept in order, may be said now to devour men and unpeople, not only villages, but towns; for wherever it is found that the sheep of any soil yield a softer and richer wool than ordinary, there the nobility and gentry, and even those holy men, the abbots not contented with the old rents which their farms yielded, nor nombre de esta deuda un completo pillaje de este país y realizará un genocidio económico sin piedad. Y en Alemania apenas aparece resistencia frente este escándalo. Una de las pocas excepciones es Günter Grass, que, sin embargo, fue maltratado por casi todos los medios de comunicación. Alemania, que una vez se autollamaba el país de los poetas y los pensadores, destruye sus raíces. Y una de estas raíces es Grecia.

Theodorakis dice en su discurso que ahora está todo el campo libre para la privatización hasta de la Acrópolis. No tengo duda de que el capital alemán es capaz de comprarla con gusto y declararla propiedad de algún banco alemán. Y los filósofos alemanes, ¿van a celebrar este fabuloso éxito? Y ¿qué dirá Hölderlin??

thinking it enough that they, living at their ease, do no good to the public, resolve to do it hurt instead of good. They stop the course of agriculture, destroying houses and towns, reserving only the churches, and enclose grounds that they may lodge their sheep in them." (http:// en.wikipedia.org/wiki/Enclosure)

2 Eso es muy consciente. Camila Vallejo, una de las voceras del movimiento chileno, decía:

"Hay que apostar a un lenguaje que le llegue hasta al más humilde, al más pobre. $\mathrm{Y}$ eso es algo que tenemos que tratar con inteligencia, sin perder el contenido. Es una recomendación, y a seguir adelante, 
que esta lucha no es solamente de los chilenos sino que es una lucha de todos los jóvenes, de todos los estudiantes de todos los pueblos en el mundo, es la lucha por la dignidad humana y por la recuperación de nuestros derechos para alcanzar esa dignidad que todos queremos, y para consolidar sociedades más humanas"

3 Smith, Adam (1983) La riqueza de las naciones (Tomo I). Barcelona: Editorial Bosch.

4 Renaut Lambert: "Los economistas de bancos en campaña". La Monde Diplomatique, Bogotá, marzo 2012, p.13 Cita como su fuente el trabajo de David Stuckler, Lawrence King y Martin McKee: "Mass privatisation and the post-communist mortality crisis: a cross-national analysis". The Lancet, volumen 373, número 9661, pp. 399 - 407, Londres 31 January 2009 revisar esta referencia bibliográfica. Se puede leer algo parecido en Naomi Klein: 2010) La doctrina del shock. El ange del capitalismo del desastre. Barcelona, Buenos Aires, México: Paidós.

5 San Pablo habla de algo que se suele traducir como pecado. Todo crimen es pecado, aunque no sea todo pecado un crimen. Por eso, corregí la traducción usual porque la palabra pecado no transmite lo que Pablo está diciendo.

Ver Hinkelammert, F. (2010) La maldición que pesa sobre la ley: las raices del pensamiento crítico en $\mathrm{Pa}$ blo de Tarso. San José: Arlekín.

6 Consultar la revista Arbeitgeber, 1/91. También el artículo de Willy Spieler: "Liberale Wirtschaftsordnung - Freiheit für die Starken?”, en: Neue Wege, septiembre de 2002, Zürich.

7 Ver el discurso de Theodorakis con el título: "La verdad sobre Grecia". http://www.contrainjerencia. $\mathrm{com} / \mathrm{p}=39245$ 